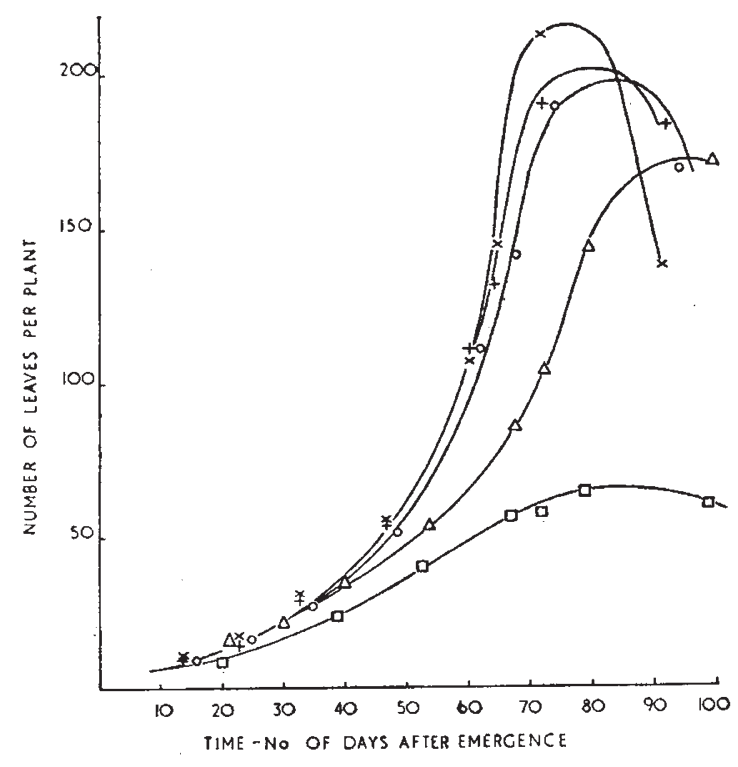

Fig. 2. Number of leaves per plant

$\Delta$ Arran Pilot ; $\square$ Ulster Chieftain ; $\times$ Majestic ; $\odot$ Stormont Thewn; + King Edward The time-scale represents the number of days from the mean

its peak size at an earlier date than these, although it had a relatively longer static pericd while the foliage area remained at a steady level. "Ulster Chieftain", an early potato, was the first (of the varieties studied) to attain its peak size, but it had a static pericd considerably longer than the other varieties. Thus if changes in vegetative growth are taken as a general indication of the distribution of the available metabolites in the plant, "Ulster Chieftain" would, as is in fact the case, be expected to begin tuber formation somewhat earlier in the season than "Arran Pilot", the latter being followed by the maincrop varieties "Majestic", "King Edward" and "Stormont Dawn".

Each variety differed in the number of leaves produced per plant and in the maximum size of the individual leaves. "Ulster Chieftain" appeared to have a slcwer rate of leaf production from the start of vegetative growth, but the individual leaves were relatively larger and thus the rate of increase in leaf area appears the same as in other varieties. "Arran Pilot" prcduced leaves at the same rate as the maincrop varieties during the initial phase of growth, but later this rate decreased with the commencement of tuber formation. "Majestic", "King Edward" and "Stormont Dawn" prcduced leaves at approximately the same rate throughout their growing pericd.

It is probable, therefore, that the potato plant exhibits a basic growth-form which is mcdified in each variety in a characteristic manner according to the stage in the growth-cycle and the rate at which the growth substances are distributed to the various organs. Scme varieties use a high proportion of the available metabolites for the prcducticn of tubers early in the season, showing a correspondingly slow growth of shoots frcm the axils of the leaves, while oppcsed to these are varieties which form their tuber initials considerably later but which show a continuing rapid differentiation of axillary shoots above grcund. Modifying this varietal grcwth-form, as manifested by increase in total leaf area, are such factors as time of planting, type of seed, and environmental conditions (including light, temperature, rainfall and soil conditions), which have been shown to affect the growth-rate of the plant to some degree $e^{3-5}$.

The help of Mrs. N. McDermott and Mr. J. D. Ivins, of the University of Nottingham School of Agriculture, is gratefully acknowledged. [Oct., 4.

1 Bald, J. G., and Hutton, E. M., Aust. J. Agric. Res., 1, 3 (1950).

' Bald, J. G., Emp. J, Exp. Agric., 14, 43 (1946).

- Glover, J., Emp. J. Exp. Agric., 15, 9 (1947).

- Werner, H. O., J. Agric. Res., 64, 257 (1942).

'Van Der Plank, J. E., Emp. J. Exp. Agric., 14, 217 (1946).

\section{GWYNNE-VAUGHAN RESEARCH LABORATORY, BIRKBECK COLLEGE, LONDON}

N January 31 at Birkbeck College, University of London, the new Gwynne-Vaughan Research Laboratory was opened by Dame Helen GwynneVaughan. The Laboratory commemorates the first two full-time heads of the Department of Botany in the College. D. T. Gwynne-Vaughan (1871-1915) was appointed in 1907 and accepted the chair of botany in the University of Belfast in 1909. He was succeeded by Dr. H. C. I. Fraser, whom he married two years later; with two periods of war service she held office until 1944.

The opening of the new Laboratory provides an occasion for reflexion for the botanists, scattered over the world, who were trained by the distinguished workers whose names it bears. Prof. D. T. GwynneVaughan was an anatomist whose work is now classical : he was particularly interested in the Filicales. A photograph on the wall of the new Laboratory shows him at work with Dr. F. Kidston on the fossil Osmundaceæ and recalls the words of Prof. F. O. Bower that, in the series of papers which resulted from that happy co-operation, "seldom have two minds blended their results more effectively". The memory of Prof. Gwynne-Vaughan's personal charm, kindliness and humour, and his distinction as a teacher, as well as a research worker, is still very vivid in the minds of his former colleagues and students.

In 1909 Dr. H. C. I. Fraser was appointed to succeed Prof. Gwynne-Vaughan, and she brought great dignity and distinction to the post. During the First World War, Mrs. Gwynne-Vaughan was posted to France as senior officer of Queen Mary's Army Auxiliary Corps; later she was sent to the Air Ministry in charge of the Women's Royal Air Force. She received a D.B.E. (Military Division) in 1919 and a civil G.B.E. "for public and scientific services" in 1929. From 1939 until 1941 she was at the War Office as director of the Auxiliary Territorial Service. Dame Helen has thus interspersed academic work of distinction with public service of the highest order.

It would be hard to find a greater contrast than exists between the old laboratories and the modern well-equipped research laboratory in the new building of Birkbeck College. The old Botany Department was extremely small. It was situated in Breams Buildings right in the city of London- the pulsations of Fleet Street on one side and the begrimed though quiet old-world, miniature gardens of Fountain Court and Staple Inn on the other. Classes were held in the evenings and on Saturday mornings. No ray of 
sunlight ever penetrated the gloom; the research laboratories consisted of odd bits of passageway and the top of a proscenium arch, cut off for the acoustic conveniences of the hall below. Printing presses in the adjoining buildings clanged the harder as week-end editions became due, dust seeped in through every crevice and no plant had the least chance of survival, unless it was a fungus safely enclosed with all its requirements in a Petri dish.

Despite the handicaps, the students who arrived from all over the Greater London area, and indeed from beyond the seas, developed enthusiasm for their work and a great affection for the Department. They carried out publishable work on a variety of topics but predominantly on either cytology or the fungi. Many of them could only hope to attain academic distinction by way of evening classes because they were fully employed all day or were unable to pay the higher fees which would have been involved elsewhere. The full-time staff working under Dame Helen was small; but it was augmented in the evenings by botanists distinguished in their own fields, who came and gave specialist courses. To us all, teachers and taught, Dame Helen was a continual source of stimulus and inspiration. She never spared herself physically and carried out her distinguished researches on the fungi, while taking the very keenest interest in her staff and students, both past and present.

Those who best knew the old building will be the first to wish that the new Laboratory, with all its facilities, may create for itself an even greater tradition, built on the solid foundation of its inheritance and under the guidance of Prof. T. Ingold, the present holder of the chair.

LILY NEWTON

\section{INDIAN OILS AND FATS AND THEIR UTILIZATION}

A SYMPOSIUM on "Indian Oils and Fats and their Utilization" was held at the National Chemical Laboratory of India, Poona, during November 7-9, 1951. Prof. J. W. McBain, director of the Laboratory and chairman of the Vegetable Oils Committee, presided.

The scope of the symposium was explained by its organizer, Dr. J. S. Aggarwal, in charge of the Oils and Fats Section of the Laboratory. He said that India is the biggest oil-seed producing country in the world, and she contributes about 20 per cent of the world's production of oil seeds. Kamla oil, which in certain respects is better than non-available tung oil, is a great potential material resource of India. Pisa fat, which is almost pure trilaurin, is perhaps avail. able only in India, but is likewise completely neglected commercially. India's large production of many oil seeds has led to industries such as seed crushing, soap and glycerine, paints and varnishes and vanaspati. Although India is almost self-sufficient as regards these commodities, there is a great shortage of oils and fats. Other industries such as vegetable oil lubricants, greases, stearic and other fatty acids and other derivatives should also be developed. Dr. Aggarwal then suggested various methods for removing the shortage of edible oils, by increasing the overall output of oil seeds, adoption of solvent extraction, increased production of fish oils, and development of a flourishing dairy industry.
Dr. S. A. Saletore, assistant director, Centra] Laboratory for Scientific and Industrial Research, Hyderabad, then gave a brief report of the Oils and Fats Symposium that was held at Hyderabad during August 12-18, 1950. Altogether, seven papers on different subjects connected with oils and fats were read and discussed at that time.

At the present symposium, forty-eight papers were read and discussed under the following seven sections: (1) oil seeds and vegetable oils ; (2) oil extraction; (3) soap and glycerine; (4) hydrogenation of oils ; (5) fish oils ; (6) castor oil, drying oils, paints and varnishes; (7) analytical and other miscellaneous papers.

\section{(i) Oil Seeds and Vegetable Oils}

Mr. I. M. Qureshi, sylviculturist, Bombay State, Poona, in his paper on "Forest Oil Seed Wealth of Bombay State", discussed the methods of increasing the yields of forest oil seeds. A survey of such forest oil-bearing plants as kamla, pisa, butter trees and others is essential. Mr. R. C. Shrivastava, agricultural chemist, Madhya Pradesha, Nagpur, spoke on "Gokhru as a Source of Vegetable Oil". One acre of land can give $500-600 \mathrm{lb}$. of gokhru seeds containing 30-33 per cent semi-drying oils. The seeds can be removed from the thorny cover by shaking in 1.5-2 per cent sulphuric acid. The cake has a high content of phosphorus and nitrogen.

Mr. S. C. Gupta (National Chemical Laboratory) gave information about the availability of kamla seeds from the forests of the Punjab, U.P., Bihar, Bengal and Bombay States. The various characteristics of the seed oil and the constitution of kamlolenic acid, the new hydroxy fatty acid constituent isolated from the oil, were discussed. Utilization of kamla oil in air-drying wrinkle finishes and for other coating materials and the prospective uses of the hydrogenated kamlolenic acids were described. The cake is a rich source of nitrogen.

In a paper entitled "Utilization of Nim Oil", Mr. C. R. Mitra (National Chemical Laboratory) discussed the various aspects of industrial utilization of the oil on the basis of the researches carried out under the Council for Scientific and Industrial Research. The process of cold alcohol extraction of the oil ensures separation of the bitter constituents and their eventual utilization in pharmaceutical industry, and at the same time leaves the oil to be utilized for production of oleic and stearic acids. The extracted oil, when refined, is as good as any other vegetable oil and can be hydrogenated, when it may be put to various industrial uses, for example, high-grade soaps or high-melting sterin.

Dr. J. G. Kane, Department of Chemical Technology, University of Bombay, pointed out the drawbacks of mowrah oil for edible purposes. These are high acidity, deep coloùr, unpleasant smell and high unsaponifiable matter. Alcoholic refining was found to be good. By hydrogenation, products similar to mutton tallow and coco-butter could be obtained.

Mr. T. V. Rao directed attention to the catastrophic increase in the prices of oils and fats compared to those of the United Kingdom, especially that of coconut oil. Difficulties in the way of soap and vanaspati industries were discussed and some remedial measures suggested.

Mr. P. K. Patnaik, special officer, Oil Co-operative, Government of Orissa, read an interesting paper on 